\title{
(2) OPEN ACCESS \\ How to talk with the family of a dying patient: anger to understanding, rage to compassion, loss to acceptance
}

\author{
Moshe Y Flugelman
}

Department of Cardiovascular Medicine, Lady Davis Carmel Medical Center, Technion Israel Institute of Technology, Haifa, Israel

\section{Correspondence to}

Professor Moshe Y Flugelman, Department of Cardiovascular Medicine, Technion Israel Institute of Technology, Haifa, Israel; myf@technion.ac.il

Received 7 February 2021 Accepted 24 June 2021 Published Online First 26 July 2021

\section{Check for updates}

(c) Author(s) (or their employer(s)) 2021. Re-use permitted under CC BY-NC. No commercial re-use. See rights and permissions. Published by BMJ.

To cite: Flugelman MY. BMJ Supportive \& Palliative Care 2021:11:418-421.

\begin{abstract}
Informing families about the impending or actual death of their relatives is one of the most challenging and complex tasks a physician may face. The following article describes goal setting and provides five roles/recommendations for conducting the encounter with patient families regarding the imminent or actual death of their relatives. Importantly, the encounter should be family-centred, and the physician should be highly attentive to family needs. The following roles should be applied based on family needs and should not be sequential as numbered. The first and basic role is to inform the family at the earliest possible time and as often as possible. The second goal of the physician is to convey to the family that their relative received the needed therapy during his hospitalisation or in the community. The third goal of the physician is to help the family reach acceptance of the death of their relative and leave the hospital having moved beyond anger and bargaining. The fourth goal of the physician during the encounters is to reduce or alleviate guilt by stating that nothing could have changed the course of the disease and that all efforts were made to save the patient. The fifth role of the physician is to try and help the family as a single entity and maintain their unity during this stressful situation. Following these roles/methods will help families in the stressful situation and will create the difference between anger and understanding, rage and compassion, and loss and acceptance.
\end{abstract}

\section{INTRODUCTION}

Informing families about the impending or actual death of their relatives or friends is one of the most challenging and complex tasks a physician may face. Needless to say, this situation is one of the most distressing life events for the family or friends. Communicating the bad news requires multiple skills and deep experience. The physician must be

\section{Key messages}

- Informing families about the impending or actual death of their relatives is one of the most stressful situations for the family and physician alike.

- Following the roles/methods described in this manuscript will create the difference between anger and understanding, rage and compassion, and loss and acceptance for the families.

able to detect and assess the psychological state of the family and understand the inter-relationships within the family. ${ }^{12}$ All this must be done in a short encounter and in the midst of a stressful situation for the family and physician alike. ${ }^{34}$ An additional essential component of the encounter is creating trust between the physician and the family. ${ }^{5} 6$ Talking to families in general, and breaking the bad news, in particular, are responsibilities that physicians first learn in medical school simulations but then develop in depth based on a lifetime of experience. Learning how to become a good listener and observer is fundamental in the making of a physician. ${ }^{7}$ Multicultural societies, religious beliefs, family structure, and previous life experiences make the interaction between the informing physician and families a multilayered and dynamic process. Like any other clinical situation, the physician must conduct a structured communication based on predefined goals for the interaction and should be attentive to text, subtext, and body language of the family members. ${ }^{4}$ The physician's first and foremost task is to listen very carefully to the family and identify their needs expressed verbally or by body language. While several approaches have been described for delivering the bad news to patients with severe conditions and incurable disease, ${ }^{12}$ the following article 
Table 1 Goals for the encounter with families of dying patients

\begin{tabular}{|c|c|}
\hline Goals during the encounter & Useful statements \\
\hline Goal 1: prepare the family for the upcoming events & $\begin{array}{l}\text { 'We are doing our best to resuscitate your relative and his condition is } \\
\text { severe' } \\
\text { 'Now I will return to be part of the treating team but I will continue to } \\
\text { update you in } 10-20 \text { min' }\end{array}$ \\
\hline Goal 2: convey to the family that their relative received the needed therapy & $\begin{array}{l}\text { 'Your relative received the best possible therapy and I believe that even in } \\
\text { the leading hospitals in the world the same therapies would be used' }\end{array}$ \\
\hline $\begin{array}{l}\text { Goal 3: help the family reach acceptance and leave the hospital accepting } \\
\text { the death of their relative }\end{array}$ & $\begin{array}{l}\text { 'It is the end', 'we stopped are efforts as biology forced us to realise it is the } \\
\text { end', 'we are sorry but we lost the battle' }\end{array}$ \\
\hline Goal 4: reduce or alleviate guilt feeling & $\begin{array}{l}\text { 'We had done everything to prevent pain' or 'your relative was fortunate } \\
\text { with such a devoted family' }\end{array}$ \\
\hline Goal 5: help the family as a single entity and maintain their unity & $\begin{array}{l}\text { 'This kind of situation can break or unite families and I am sure that your } \\
\text { relative's wish was that you will unite' }\end{array}$ \\
\hline
\end{tabular}

concentrates on informing families about the impending or actual death of their relatives. More specifically, the article describes goal setting and how to use exemplary methods to address families' needs when the death of a relative or friend is imminent (table 1 and box 1). While the current manuscript shares many aspects of previous publications, ${ }^{12}$ the focus of this manuscript is on the communication with families of dying patients and on providing practical roles for the encounter. Unlike other methods such as CLASS and SPIKE, the following roles are directed to families of the acutely ill, ${ }^{128}$ mostly patients without cancer, many of whom are elderly patients with multiple comorbidities. ${ }^{9}$ The situation of patients with comorbidities or acute illness can deteriorate rapidly and the family finds itself in the waiting room or corridor of an intensive care unit unprepared and deprived of communication with the patients and the treating team. ${ }^{10}$ Such an unfortunate situation, if not managed properly, can lead to severe grief and post-traumatic stress disorder. ${ }^{11}{ }^{12}$ In many

Box 1 Simple roles for the encounter with families to inform the impending death or death of their relatives

- Always speak to the family in a separate room while sitting.

- Present yourself and ask who is present and who is missing. Present yourself again in every encounter.

- Share attention with all family members but try to identify the person that leads the family.

- Do not use medical terms and use simple language. Repeat the message more than once.

- Allow the family to ask questions when time allows.

- Speak to the family as often as possible. Take time even during resuscitation to sit down and talk to the family.

- The truth must be said, but it should be introduced gradually.

- Offer administrative help to the family and do not leave a single family member alone.

- Set the goals for the encounter and make sure all goals are fulfilled. Use phrases as the ones detailed in table 1.

- Overwhelming emotions are common. instances, after trying to save the patient's life, the treating team concludes that additional measures may be futile, and the treatment goals should be modified. This manuscript will help the physician to manage the situation and help the family to get through this immediate phase of losing a relative or a friend.

\section{Setting goals}

The five roles/methods outlined in this manuscript should be adjusted to the needs of the families. Except for the first role of early and multiple interactions with the family, the other goals/methods should be used flexibly based on the needs of the family. In many instances, families will ask for administrative help such as calling someone from the family. Such requests should be addressed promptly and confirmed with the family to be able to focus on the following issues and to create trust.

Many deaths in the hospital and at home are considered by medical teams as inevitable despite the fact that the condition of the patient prior to the acute illness was good. ${ }^{913}$ These deaths usually involve older individuals with chronic diseases or individuals with incurable diseases. ${ }^{913}$ Despite the predictable downhill course and inevitability of death, in many instances, the impending or actual death often comes as a shock to the family, and the need for information and clinical updates from the treating team is acute. Based on this observation, the first goal of the physician is to prepare the family for the upcoming events. Several strategies can be employed to achieve this goal. The most important one is to inform the families of an impending death and not on the terminal event of death. The first and basic role is to inform the family at the earliest possible time and as often as possible. During resuscitation or terminal stages of the disease, the physician should talk to the family in a room (not in the corridor). After introducing himself, the physician should ask who is present in the room and which family members are missing. Then the physician should describe the situation of the patient. Sentences such as 'we are doing our best to resuscitate your relative and 
his condition is severe' should be used. The language used should be free of complex medical terms and the message of the severity (gravity) of the situation must be repeated several times. At the end of the meeting, the physician can excuse himself and return to the team treating the patient, but should signal that communication will be ongoing and continuing by stating 'now I will return to be part of the treating team but I will continue to update you in 10-20 min'.

More than one meeting provides time for the family to establish an interfamily support system between the meetings with the physician. ${ }^{14}$ Also, the message of impending death provides a gradual understanding of the gravity of the situation.

Most patients nowadays require multiple interventions during hospitalisation. There are hundreds of interactions with the medical team including multiple conversations, administration of medications, and diagnostic and therapeutic procedures. During these interactions, there may be several instances that are associated with dismay on part of the patient or his family. Although these events may be of minor importance, they influence the relationship and create distrust between the family and the medical team. Thus, the second goal of the physician is to convey to the family that their relative received the needed therapy during his hospitalisation or in the community. Knowing that their relative received quality medicine and that all efforts were done to save the patient's life is in many instances comforting to the family. Sentences such as 'your relative received the best possible therapy and I believe that even in the leading hospitals in the world the same therapies would be used' help families overcome the immediate sense of grief at the loss of their relative. Of course, such statements must be accurate. In case only limited resources are available locally, it is crucial to state that the maximum effort possible had been made. In case an error occurred and led to the deterioration and death of the patient, it should be stated in the first meeting; however, strategies to deal with errors are not part of the current manuscript.

The finality of death is always the greatest fear for families even when death is expected. Acceptance of death is a process that has several steps as described for grief in the Kübler-Ross model. ${ }^{1516}$ Although this model is challenged, the variability of response by different families and the dynamic evolution of the response of the families are evident in most encounters. ${ }^{17}$ The nonlinearity of family responses requires attention from the treating team and flexibility in responses to family needs. In addition, in many encounters the five stages described by Kübler-Ross are manifested on an accelerated timeline. Denial, anger, bargaining, depression and acceptance are often expressed by the families but not always in the order described. The third goal of the physician is to help the family reach acceptance of the death of their relative and leave the hospital having moved beyond anger and bargaining. Anger and bargaining after leaving the hospital can fuel frustration, depression and guilt which threaten the integrity of families. ${ }^{18}$ Sentences like 'it is the end', 'we stopped our efforts as biology forced us to realise it is the end', 'we are sorry but we lost the battle' can be both comforting and allow family members to accept the finality of death.

Feelings of guilt related to the death of a relative are very common. These feelings are fuelled by lack of attention to early signs of disease, low investmentboth emotional and financial-during the course of the disease, and absence or lack of attention during critical parts of the illness. The fourth goal of the physician during the encounters is to reduce or alleviate guilt by stating that nothing could have changed the course of the disease and that all efforts were made to save the patient. Focused, brief discussion of the points that cause the feelings of guilt is appropriate and can be initiated if the physician suspects that such emotions are present. Comforting sentences such as 'we had done everything to prevent pain' or 'your relative was fortunate with such a devoted family' should be repeated several times to allow them to be processed by the family. In case the family members are torn as they feel they gave up on their relative and they feel they betrayed his trust and love, a sentence such as 'to love, sometimes means to let go' can be used as part of the description of the potential outcome of continued resuscitation efforts in comparison with finalising the resuscitation efforts. Describing the futile outcome of brain death and vegetative existence in comparison with keen effort to save the patient and then a realistic decision to terminate efforts should be discussed with families to help them overcome their dilemmas. The importance of respectful existence and patient's autonomy should be discussed in such situations.

Multimember families may have differences of opinion regarding the illness and its management. These differences are amplified during the stressful circumstances of impending and actual death and can create family disintegration. During the encounters, sometimes, family members who have boycotted one another may find themselves sitting in the same room for the first time in years. The fifth role of the physician is to try and help the family as a single entity and maintain their unity during this stressful situation. Statements such as 'this kind of situation can break or unite families and I am sure that your relative's wish is that you will unite' or 'this is an opportunity to leave aside old issues and unite the family again' can be extremely helpful.

In summary, the encounter with families of dying patients should be structured based on the five goals detailed above. The physician must listen, observe and identify families' needs during the encounter or encounters. All or just a single goal/method of the five goals described above can be applied or accomplished based on the circumstances and the needs of the family. The use of 
the goals/methods can be adjusted at different sequences and combinations to serve family's needs.

A letter that I received from a family of a patient who died in our intensive care unit highlighted the importance of the encounter with the physician during the impending and subsequent death of their father. The family wrote in their letter that they felt that everything was done to save the life of their father and that the encounters with the physician created the difference between 'anger and understanding, rage and compassion, and loss and acceptance'.

\section{Corona pandemic's impact on talking to the family of a dying patient}

The corona pandemic imposed additional challenges to the encounter with families of dying patients. The physical isolation and the risk of frequent meetings with the families dictate several adjustments of the above recommendations. Face-to-face meetings should be replaced with phone or video calls but should be frequent. Seeing the dying patient with COVID-19 using cameras in the control rooms or entering the corona department with appropriate personal protection dressing should be employed whenever possible. The content of the phone calls or video meetings with the families should be similar to face-to-face meetings and should include references to the fact that social isolation and risk of contracting COVID-19 limit the face-to-face meetings.

Contributors MYF planned, researched and wrote this manuscript.

Funding The authors have not declared a specific grant for this research from any funding agency in the public, commercial or not-for-profit sectors.

Competing interests None declared.

Patient consent for publication Not required.

Provenance and peer review Not commissioned; externally peer reviewed.

Open access This is an open access article distributed in accordance with the Creative Commons Attribution Non Commercial (CC BY-NC 4.0) license, which permits others to distribute, remix, adapt, build upon this work noncommercially, and license their derivative works on different terms, provided the original work is properly cited, appropriate credit is given, any changes made indicated, and the use is noncommercial. See: http://creativecommons.org/licenses/by-nc/4. $0 /$.

\section{ORCID iD}

Moshe Y Flugelman http://orcid.org/0000-0003-0874-4912

\section{REFERENCES}

1 Baile WF, Buckman R, Lenzi R, et al. SPIKES-a six-step protocol for delivering bad news: application to the patient with cancer. Oncologist 2000;5:302-11.

2 VandeKieft GK. Breaking bad news. Am Fam Physician 2001;64:1975-8.

3 Brown R, Dunn S, Byrnes K, et al. Doctors' stress responses and poor communication performance in simulated bad-news consultations. Acad Med 2009;84:1595-602.

4 Corless IB, Limbo R, Bousso RS, et al. Languages of grief : a model for understanding the expressions of the bereaved. Health Psychol Behav Med 2014;2:132-43.

5 Flugelman MY, Jaffe R, Luria G, et al. Trust in the referring physician reduces anxiety in an integrated community-tohospital care system. Isr J Health Policy Res 2020;9:7.

6 Flugelman MY. History-taking revisited: simple techniques to foster patient collaboration, improve data attainment, and establish trust with the patient: simple techniques to foster patient collaboration, improve data attainment, and establish trust with the patient. GMS J Med Educ. In Press;2021.

7 Boudreau JD, Cassell E, Fuks A. Preparing medical students to become attentive listeners. Med Teach 2009;31:22-9.

8 Foley K. A 44-year-old woman with severe pain at the end of life. JAMA 1999;281:1937-45.

9 Karkabi B, Khoury R, Zafrir B, et al. Causes of mortality in a department of cardiology over a 15-year period. Int J Cardiol Heart Vasc 2021;32:100692.

10 Kirchhoff KT, Walker L, Hutton A, et al. The vortex: families' experiences with death in the intensive care unit. Am J Crit Care 2002;11:200-9.

11 Kross EK, Engelberg RA, Gries CJ, et al. ICU care associated with symptoms of depression and posttraumatic stress disorder among family members of patients who die in the ICU. Chest 2011;139:795-801.

12 Downar J, Koo E, des Ordons AR, et al. Prevalence and predictors of severe grief reactions and desire for support following a death in the intensive care unit: a multicentre observational study. Intensive Care Med 2018;44:521-2.

13 Rhee C, Jones TM, Hamad Y. Centers for disease control and prevention (CDC) prevention epicenters program. prevalence, underlying causes, and preventability of sepsis-associated mortality in US acute care hospitals. JAMA Network Open 2019;2:e187571.

14 Näppä U, Lundgren A-B, Axelsson B. The effect of bereavement groups on grief, anxiety, and depression - a controlled, prospective intervention study. BMC Palliat Care 2016;15:58.

15 Kobler-Ross E. On death and dying. McMillan Co, 1969.

16 Kubler-Ross E. The family physician and the dying patient. Can Fam Physician 1972;18:79-83.

17 Stroebe M, Schut H, Boerner K. Cautioning health-care professionals: bereaved persons are misguided through the stages of grief. Omega 2017;74:455-72.

18 Stroebe M, Stroebe W, van de Schoot R, et al. Guilt in bereavement: the role of self-blame and regret in coping with loss. PLoS One 2014;9:e96606. 